\title{
La columna con gancho de Manuel Alcántara o las reminiscencias de un ex cronista de boxeo
}

\section{The Manuel Alcantara's Attractive Column or the}

\section{Reminiscences of a Former Boxing Journalist}

\section{Emy Armañanzas Sodupe, profesora de Periodismo. Universidad del País Vasco}

Fernando Sánchez Gómez, investigador. Universidad del País Vasco

Recibido: 19-XII-2008 - Aceptado: 3-II-2009

Resumen:

Las expresiones del boxeo conforman un lugar común empleado frecuentemente fuera de este ámbito: “peso pesado de la política”, "encajar un duro golpe”, entre otras. Encontramos estos referentes en las columnas personales que Manuel Alcántara publica en Vocento. La regularidad y el modo de aparición de tan agonístico ítem se analizan en una muestra aleatoria de 1.500 columnas personales publicadas entre 1983 y 2008.

Palabras Clave:

Manuel Alcántara, géneros de opinión, columna personal, boxeo, agôn, retórica.

Abstract:

Boxing expressions that are often used in diferent areas are topoi as 'heavy weight of politics' or 'fit a coup', among others. We have found this agonistic item in Manuel Alcantara's personal columns published in Vocento. This paper reviews a sample of 1.500 columns signed by him and published in Vocento inc. between 1983 and 2008.

Key words:

Manuel Alcantara, commets, personal column, boxing, agôn, rhetoric. 


\section{Introducción: Manuel Alcántara, cronista de boxeo}

Manuel Alcántara fue durante once años cronista de boxeo en el diario deportivo Marca, redacción donde entró en sustitución de otro veterano campeón de la crónica pugilística: el escritor Fernando Vadillo, que había fichado por el recién nacido As.

Entre 1967 y 1978, durante la segunda 'Edad de Oro del boxeo’ español, Alcántara firmó las crónicas, reportajes, entrevistas y artículos de opinión especializados en el pugilismo en la publicación que cumple en 2008 su setenta aniversario (Toro, 2008).

Alcántara desarrolló dichos géneros de manera diferenciada, esto es, respetando las reglas de la escritura periodística de cada uno y con la voluntad de estilo que le caracteriza.

Desde las páginas de Marca, Alcántara es uno de los pioneros en hacer new journalism en España; en sus textos encontramos las características literarias del Nuevo Periodismo Español (Chillón, 1999), en su forma hispánica de periodismo de creación (Bernàl y Chillón, 1985).

Este ex cronista experto en el llamado 'noble arte’ -«de boxeo sé más que de Quevedo», le confesará Alcántara a Avilés Zugasti (2005: 15)-, está considerado uno de nuestros más brillantes periodistas deportivos.

\section{Planteamiento y objetivos de esta investigación}

Del pugilato, especialidad del periodismo deportivo de Alcántara en Marca de 1967 a 1978, nos hemos ocupado en otras investigaciones (Armañanzas, 2008; Armañanzas y Sánchez Gómez, 2009).

Tratándose el autor, en cierto modo, de un agonoteta textual cabe preguntarse si el boxeo tendrá también una presencia significativa en sus columnas personales diarias en la prensa generalista (Vocento).

Por la mencionada razón, trasladamos el análisis de tan agonístico ítem retomando el tema del boxeo, ahora como lugar común (Albadalejo, 1993; Lausberg, 1999) de sus columnas. Con este fin, nos fijamos en el modo en que Alcántara trata este tema en sus columnas personales en El Correo, periódico de información general del Grupo Vocento, que reproduce su columna diaria en doce de sus trece cabeceras: El Diario Vasco, El Correo, El Diario Montañés, La Verdad, Ideal, Hoy, Sur, La Rioja, El Norte de Castilla, El Comercio, La Voz de Cádiz y Las Provincias.

Estos periódicos suman el mayor número de lectores de la prensa editada en España: más de 5’5 millones, según la tercera oleada de 2008 del EGM. Sin contar otros como El Diario de Navarra que también publica su columna, al margen del citado Grupo.

$96\left|n^{\circ} 8\right|$ doxa.comunicación 
Cualquier oportunidad de analizar su escritura nos parece justificada tratándose, en el momento de hacer nuestro estudio, de la firma más difundida de España que cumplió en 2008 los 50 años de profesión periodística.

El marco teórico de este artículo de investigación, centrado en la columna personal, debe adecuarse a las características textuales de los géneros periodísticos según la diferenciación con que hemos dicho que el propio Alcántara los trabaja. Apoyamos esta distinción, apreciable como decimos en su práctica profesional, y recurrimos a la teoría de los Géneros de Opinión que diferencia nítidamente entre la columna y el artículo (Armañanzas, 1995, 1996).

Hacer esta singularización de géneros de opinión resulta imprescindible porque al haberlos trabajado el propio Alcántara de manera diferente, no pueden, en consecuencia, considerarse equivalentes, de una parte el artículo de boxeo que firmaba en Marca (opinión de un especialista al que se le encarga escribir sobre un tema que domina: el boxeo; con ubicación y periodicidad de aparición irregulares), y de otra, su columna personal diaria en Vocento (columna de actualidad, de tema libre, que se publica en contraportada con periodicidad fija).

En el primer caso, el boxeo es el motivo central, la clave que sostiene todo su artículo como experto; en el segundo -el que analizamos aquí- Alcántara toma cualquier tema de actualidad como centro de atención de su columna personal y recurre tangencialmente al boxeo para establecer analogías, comparaciones con situaciones y personajes que nada tienen que ver con el pugilismo.

La importancia del boxeo como referente discursivo en Alcántara radica en que este motivo ha estado presente en sus columnas personales - con la regularidad que revela esta investigación- a lo largo de tres décadas, aflorando, aún en la actualidad, bajo distintas formas poéticas y retóricas (Albadalejo, 1993). Todo ello, en virtud de la máxima libertad de escritura y selección temática que tiene todo columnista personal.

Para realizar esta investigación se ha tomado una muestra aleatoria de 1.500 columnas personales de Manuel Alcántara publicadas en El Correo (Vocento), pertenecientes a distintas épocas entre 1983 y 2008.

\section{La columna personal}

La columna personal es el texto de opinión que ocupa un espacio de ubicación fija en alguna de las secciones de una publicación periódica, diferenciada tipográficamente y casi siempre con título genérico, que indica que está reservada a un columnista, periodista o no, que con periodicidad y extensión determinadas enjuicia cualquier tema, generalmente de actualidad. En la columna personal, la más literaria de todas, el 
autor da rienda suelta a su propio estilo así como a la elección de los temas, al enfoque ideológico y al planteamiento estructural de la misma a través de los que muestra su yo. A diferencia de lo que ocurre con otros textos de opinión, con la columna personal sus seguidores saben perfectamente dónde y cuándo pueden encontrarla, (Armañanzas, 1995: 180 y 215-229).

La columna personal es, por sus requisitos de estilo, la tipología más atractiva y la más apreciada por el gran público. Y los columnistas -lo que Antonio Burgos (1999) llama apasionadamente «la cofradía de la columna»-son los cofrades con mayor número de seguidores de la prensa. Recuérdese a Umbral, Campmany, Vázquez Montalbán, Cándido y a tantos otros desde que Larra comenzase a perfilar el género con más literatura del periódico.

Los directores de periódicos confían la columna a escritores y periodistas de éxito, es decir, a profesionales con la competencia poética necesaria para el desempeño de una tarea periodística que requiere la máxima brillantez de estilo. En los últimos años, la autoría de la columna personal se ha extendido a firmas conocidas del gran público: cocineros, presentadores de televisión, gente del cine, del teatro, de la música, entre otros ámbitos de gran impacto mediático.

\subsection{La columna personal de Manuel Alcántara}

Se publica los siete días de la semana, sin un título genérico, aunque a lo largo de su trayectoria Alcántara haya ideado distintos epígrafes señalando su espacio reservado: 'Vuelta de hoja', 'A beneficio de inventario', 'Luz de domingo', ‘Galería', 'Punto cardinal', 'Tribunal del viento' o el gongorino 'Oficio de ver', entre otros.

En su columna personal, este autor le hace sitio a una serie de lugares comunes, entre los que se encuentra el boxeo. Son los tópicos de su escritura. El mundo íntimo de Manuel Alcántara, donde revela sus gustos, sus aficiones, su particular interpretación de la realidad, incluso sus prioridades personales. En definitiva, se trata de la manera que tiene el columnista de mostrarse ante su público.

Este 'yo' del comunicador activa un tipo de mecanismo persuasivo que la retórica aristotélica ha llamado ethos. López Pan $(1995,1996)$ lo ha traducido como 'talante' y lo considera el principal elemento configurador de esta clase de columnas.

Veamos un ejemplo con los gratos recuerdos de cuando Alcántara hacía la crónica de boxeo en el diario Marca, «los más alegres de mi vida»: 
[...] Una vez, cuando yo hacía la crónica de boxeo en el diario Marca, en los años más alegres de mi vida y los mejores del pugilismo español, el respetable público formó un escándalo, al creer que un combate estaba amañado [...], «El público, tan respetable», 04.03.98, u.p.

En palabras de Perelman y Olbrechts Tyteca (1989: 490), muy apropiadas para el caso del Alcántara columnista personal, con el ethos «el orador proporciona un contexto al discurso». Este contexto es el creado por el propio columnista que se cuenta en su columna.

\subsection{La cita fija del columnista con sus 'seguidores'}

La columna personal ofrece al lector la ocasión de acercarse a las firmas que le atraen, bien por la idiosincrasia de las mismas o por sus posicionamientos ante mil temas que le interesan. El propio Alcántara explica el secreto del interés de su lectura (Avilés Zugasti, op. cit., p. 14): «Yo creo que tienes mucho ganado si escribes sobre algo de lo que esté hablando la gente, por eso me gusta ir por los bares, y preguntar, y hablar. Porque el tema del día no siempre es el que viene en las portadas de los periódicos, en ellos se sigue otra valoración. No hay que perder nunca el contacto con la gente, con el pueblo y con la calle».

La visión genuina del columnista personal ante cualquier asunto provoca el interés de los lectores, que quieren saber qué opina esa firma que se les muestra tan próxima en su columna. Estos lectores, que siguen una columna diaria, acaban alcanzando un grado de familiaridad tal con el columnista que les lleva a buscar expresamente esa opinión particular, ese matiz, esa nota de humor propio ante los diversos asuntos que sólo sabe darles esa persona que se cita puntualmente con ellos.

Así se entiende que cuando un columnista cambia de periódico puede arrastrar tras él a parte del público, incluso espantar a los del nuevo diario, recuérdese la «infidelidad de ida y vuelta» de Umbral (Ramírez, 2007: u.p.) que causó la baja de numerosos suscriptores durante su breve paso por $A B C$.

Por eso, en el caso de la columna personal, más que de lectores (que serían los esporádicos) o de audiencia (que resulta demasiado genérica) habría que hablar mejor de 'seguidores'. Lo que en el argot deportivo serían 'hinchas', por esa cita -encuentro constante- con una firma concreta.

El público sabe dónde y cuándo encontrar una columna determinada entre todos los textos del periódico. Es precisamente aquí donde cobra toda su importancia la ubicación y la periodicidad fijas; no son características anecdóticas de la columna. Piénsese en el caso de un articulista al que no podemos leer cuando queremos, sino solo cuando el periódico nos lo ofrece que, además, desconocemos cuándo será. 


\section{El lenguaje de la columna personal}

El lenguaje de la columna personal (nivel de la elocutio) es, en realidad, el lenguaje del propio columnista, «amanuense de sí mismo». Por eso está hecho con los giros que le son propios, las palabras que inventa, las comparaciones que establece basándose en su mundo íntimo.

Fue González-Ruano quien acuñó la expresión ‘estar escrito’ siempre que terminaba no de escribir, sino de escribirse, esto es, de contarse líricamente en sus colaboraciones de prensa. Así lo recuerda Alcántara en su semblanza (1979: 14): «César más que escribir se escribía. Quizá por eso, a última hora de la mañana afirmaba que ya podía establecerse la tertulia: "Ya estoy escrito"».

En la columna personal hay tantos lenguajes como autores. Por eso se explica que su léxico resulte «de lo más variado. En un mismo texto se pueden codear las expresiones más barrocas con el lenguaje más frío, más sobrio; lo más culto con lo más popular, con el argot de diversa procedencia, con refranes, modismos, vocablos en desuso e, incluso, neologismos. La prosa de la columna personal es rica en recursos retóricos, adjetivos, interjecciones y admiraciones, suele ser colorista, de expresión brillante y con personalidad propia. Es un léxico totalmente heterogéneo que se escapa de lo cotidiano, de la expresión plana. Un lenguaje que puede llegar a ser muy creativo.», (Armañanzas, op.cit., 221).

\subsection{La prosa de guardia cambiada de un ex cronista de boxeo}

En las columnas personales de Alcántara abunda toda esta riqueza léxica que acaba de mencionarse. Si se añade el boxeo como recuerdo vital que acompaña al ex cronista, es lógico que el tema pugilístico sea uno de los lugares estables de su inspiración a la hora de escribir estas columnas.

Del pugilato, en concreto, de lo que se conoce como 'guardia cambiada', deriva la característica que más particulariza el lenguaje periodístico de Manuel Alcántara: la sorpresa que pilla desprevenido al lector, al igual que al boxeador diestro cuando pelea con un zurdo.

En el boxeo, decimos, además de encontrarse un motivo inspirador de imágenes y figuras poéticas, se halla la explicación para los constantes quiebros -'muletazos', los denomina el propio Alcántara- que el columnista hace en dichos populares, sentencias, máximas, refranes y todo tipo de frases hechas.

El lector se sorprende gratamente con dicho recurso poético, ya que el cambio que hace en un significante conocido y desgastado por el uso, genera un nuevo significado. El desplazamiento semántico proporciona a la nueva exprexión un sentido renovado, de mayor potencialidad expresiva en el contexto particular en que lo usa el columnista. 
Esta influencia estilística que tiene el boxeo en las columnas personales de Alcántara es lo que, con muchísimo acierto, el cineasta José Luis Garci, ha bautizado (1998: 12) como «la prosa de guardia cambiada».

\section{La cultura en la columna personal}

En la columna se cumple la máxima de que a mayor cultura del autor, mayor número de recursos expresivos, esto es, más competencia lingüística, retórica, poética. De hecho, resulta enriquecedor para el columnista «contar con una cultura propia, cuanto más amplia y más profunda mejor», (Armañanzas y Díaz Noci, 1996: 126).

Esta cultura es la que dota al opinante del criterio suficiente para pronunciarse sobre los distintos temas de actualidad. Cuantas más lecturas y de mayor calidad tenga, mayores posibilidades de situar los hechos en un contexto más amplio, relacionándolos con los del pasado u otros ámbitos del conocimiento humano.

La columna personal también admite la incorporación en el texto de otro tipo de saber: el de la experiencia profesional.

\subsection{La sabiduría de un veterano -y galardonado-campeón del Periodismo}

Junto con la cultura del columnista, los premios recibidos también contribuyen a incrementar el prestigio de una firma de cara a sus seguidores. La trayectoria poética (Premio Nacional de Literatura en 1963) y periodística de Alcántara ha sido reconocida, entre otros muchos galardones, con los tres premios mayores del periodismo español (el Luca de Tena, el Mariano de Cavia y el González-Ruano); por lo que pertenece al «club de los cinco». Denominación que designa a los únicos cinco periodistas y escritores en periódicos que los han recibido: Carlos Luis Álvarez Cándido, Emilio Romero, Jaime Campmany, Luis María Anson y el propio Manuel Alcántara.

Pero no sólo los premios le han reconocido su calidad periodística, sino la propia profesión. Al hacer la historia de Marca con motivo del 70 cumpleaños de la publicación, su actual director, Eduardo Inda (2008: 12), lo recuerda entre los grandes periodistas (Valencia, Cronos, Piernavieja, Vadillo, Alcántara) de una primera edad de oro de este diario deportivo o «deportista», como diría Giménez Caballero (2000: 13).

Inda (ibid.) califica a estos profesionales de «mentes privilegiadas» $\mathrm{y}$ «excelsas plumas» no sólo del periodismo deportivo sino del periodismo en general, al que dieron «algunas de las más bellas páginas» de la historia de la prensa de este país: «En la forma y en el fondo. Eran tan buenos periodistas como literatos y, consecuentemente, hacían de una noticia una obra de arte». 
En las columnas personales de Alcántara apreciamos la sabiduría poética que le es propia por su oficio de poeta y su experiencia profesional en Marca como periodista deportivo especializado en boxeo.

\section{La argumentación en la columna personal}

La argumentación o razonamiento discursivo de Manuel Alcántara en sus columnas se compone de probatio (presentación de las pruebas favorables a la posición defendida por el columnista) y refutatio (destrucción de las pruebas esgrimidas por la parte contraria).

Las varias pruebas que aporta el columnista, llamadas también argumentos, conforman el cuerpo argumentativo de su columna. El autor las va incluyendo tomando para ello la figura poética más adecuada en cada momento. Así, en el ejemplo n 2, para referirse a todas las cosas que no le dejan hacer los gobernantes, despliega una enumeración cuyo clímax se alcanza en el colmo de no poder salir a la calle por mor de la inseguridad ciudadana:

[...] Más trabajo va a costarme la alteración de otras costumbres que, aunque sean malas, me han sentado divinamente. No puedo fumar en mis restaurantes favoritos, se ha acabado el boxeo y quieren acabar con los toros, traman la subida del precio de todas las bebidas que no se obtengan abriendo cualquier grifo de nuestro hogar y no es recomendable salir de noche porque hay más ladrones que ventanas [...], en «Las horas cambiadas», 18.01.06, u.p.

En el no 3, se opta por una expresión desmesurada o hipérbole:

[...] De todo lo que puede verse en televisión, lo menos violento son los combates de boxeo que transmite, con dichosa frecuencia, Eurosport [...], en «Muertos remotos», 16.05.98, u.p.

Los ejemplos no 4 y no 5 ofrecen el recurso a la intertextualidad. En el primero hace suyo el deporte de «trepar al taburete de los bares», que era también el favorito del cronista de boxeo del Tribune Eddie Lewis en Más dura será la caída (Schulberg, 1970: 156). En el segundo introduce una expresión de la épica medieval que toma prestada del Poema de mio Cid (2005: 23) con la imagen del combate nulo de fondo:

[...] El deporte más duro que he practicado, aparte del boxeo, ha sido el de subirme a los taburetes de los bares [...], en «La mujer del ciclista», 01.08.02, u.p.

[...] Los señores no son buenos, pero los vasallos tampoco. Tales para cuales. Combate nulo [...], en «La hermosa gente», 25.11.01, u.p. 
Las pruebas -o argumentos- encontrados en sus textos son de dos tipos. Los que emplea sin una elaboración técnica o arte retórica: el hecho de actualidad que sirve de arranque al texto, tomado del periódico o de la calle. Y las que sí son fruto de su técnica o arte poético, y que se conocen como 'pruebas artificiales' (Lausberg, op. cit.). En el caso de Alcántara, se trata de los argumentos y ejemplos con los que argumenta ingeniosamente a favor o en contra.

\subsection{El boxeo como referente en las columnas de Manuel Alcántara}

Nuestro autor trae el referente de las pindáricas «luchas a puñetazos» a sus columnas con el fin de incorporarlo a sus argumentos. El boxeo conforma un lugar común de su escritura periodística. Por lugares comunes (loci) podemos entender los depósitos de ideas de los que Alcántara toma los pensamientos que mejor le convengan en cada ocasión (Lausberg, 1991:313).

La clasificación de los loci o topoi resulta de la división del mundo que hace la Retórica, por la que se obtiene una sistematización de la realidad y, por tanto, de todo posible referente discursivo. Estos referentes discursivos son el conjunto de «seres, estados, procesos, acciones e ideas que en dicho texto van a ser representados». (Albadalejo, op. cit. 73, 95).

Los lugares comunes pueden estar referidos a cualquier cosa, «lo mismo a cuestiones de justicia que de física, de política o de otras muchas materias que difieren por la especie (...)», (Aristóteles, 1999: 190, 191). En las columnas diarias de Alcántara, junto al lugar que ocupa el pugilato, aparecen el mar Mediterráneo, su infancia bombardeada de niño de la guerra, el fútbol, entre otros tópicos. Es su «depósito de argumentos», que diría Cicerón (en Perelman y Olbrechts Tyteca, 1989: 145).

En este artículo de investigación, como se ha anunciado, solo se consideran los referentes de orden agonístico (Armañanzas, 1993). En el análisis de su columna destacamos a los boxeadores que cita por su nombre (cfr. 6.1.); las comparaciones entre la situación límite de los luchadores que suben al ring con los procesos en que se encuentran sumidos los personajes protagonistas de la actualidad, políticos por lo general (cfr. 6.3. y 6.4.).

Asimismo, el columnista relaciona el tema de la redención social a través del boxeo con los nuevos marginados, los inmigrantes (cfr. 6.2.). También puede incluir comentarios pugilísticos propios o recurrir a argumentos de autoridad de otro experto (cfr. 6.5.)

La operación retórica donde se producen los hallazgos que servirán de prueba argumentativa al propósito del columnista es la inventio (Albadalejo, op. cit. p. 73) y cuando el boxeo es el elemento que configura se- 
mánticamente la columna, de manera alegórica en los ejemplos 6 y 7, alcanza también a los niveles de la dispositio y la elocutio:

[...] Estamos en los primeros asaltos del combate electoral andaluz y aún no ha llegado la hora de fajarse. Por el momento se hacen fintas y amagos, se estudia el estilo del rival y se plantea la estrategia adecuada (...) Apenas se han intercambiado algunos golpes aislados que no son más que un anuncio de lo que puede deparar el match [...], en «El guardarropa», 11.06.90.

[...] Ya que en los regímenes democráticos están prohibidos los golpes de Estado, ambos se conforman con darse golpes bajos. Los pupilos de ambos púgiles no se paran ni en barras ni en estrellas. Quieren ganar como sea. Uno recuerda que su contrario es viejo, como si pudiera ocultar su edad, y el otro insinúa que su oponente es negro, como si eso no saltara a la vista. Mejor estratega parece que está resultando Obama, que se apunta los últimos asaltos (...) La verdad es que ambos esforzados aspirantes, el del pelo blanco y el de la epidermis oscura, han agotado los procedimientos tradicionales [...], «Obama en Hawai», 24.10.08, u.p.

\section{Análisis de los datos}

Hemos encontrando referencias pugilísticas en 75 de las 1.500 columnas analizadas de Manuel Alcántara, lo que equivale al 5\% de la muestra; 5 de estas columnas están expresamente dedicadas al tema del boxeo.

De las 70 columnas que tratan de temas de actualidad ajenos al boxeo, este aparece como referente de la inventio en 60 y hay 10 que lo tienen además como el principal elemento configurador discursivo de la dispositio y la elocutio.

Con independencia del grado de intensidad textual con que se dé el pugilato en las columnas de la muestra, los ejemplos que reproducimos en este punto nos muestran lo presente que está el mundo pugilístico en el recuerdo de este ex cronista de boxeo, incluso hoy día, más de treinta años después de abandonar el ejercicio profesional del periodismo deportivo en Marca.

\subsection{Los grandes nombres del pugilato}

Dentro del primer grupo de referentes del boxeo, Alcántara ha introducido en el periodo analizado de sus columnas a siete púgiles. A Ray ‘Sugar’ Robinson, peso medio, uno de los dos grandes campeones de los años 40 sobre el que Manuel Alcántara muestra su gran admiración. De este púgil dotado de gran técnica, que terminó su vida profesional como bailarín de claqué, afirma el columnista que: 
[...] De niño quería ser Flash Gordon; de adolescente me hubiera gustado ser Ray 'Sugar' Robinson; de joven, Quevedo, y ahora, cuando por fin he comprendido que lo más importante que puede hacer una persona es sobreponerse, me conformaría con ser Zorba el griego [...], en «Pimpinela en Barcelona», 19.08.01. El Correo, u.p.

[...] Lo envidio [a Yves Montand] como a Quevedo o a Ray ‘Sugar’ Robinson [...], en «Las cosas de los demás», 17.05.04, u.p.

[...] Qué daría yo por una pluma de Quevedo o por unos guantes de Ray Sugar Robinson [...], en «Reliquias», 16.04.92.

El otro campeón citado, que contaba también con gran técnica y coetáneo del anterior, fue Joe Louis, de largo reinado sobre el cuadrilátero ya que mantuvo su hegemonía durante casi una década:

[...] Cuenta Luther King el ajusticiamiento de un negro, que como no tenía a nadie a quien encomendarse, le rezaba al ‘Bombardero’ de Detroit: «Sálvame, Joe Louis, sálvame». Hasta hace muy poco tiempo, los hombres y las mujeres de epidermis oscura sólo tenían dos tablas de salvación: la madera de las tarimas del jazz o la madera del ring [...], en «Resistencia de los metales», 07.11.08, u.p.

Manuel Alcántara es un gran admirador de los grandes pesos norteamericanos, a partir del citado Joe Louis, todos ellos negros a excepción del efímero sueco Ingerman Johansson y de Rocky Marciano, cuyo nombre le puso a su perro:

[...] los perros y los gatos son otro cantar. Yo los he hecho compatibles y se llevaban muy bien. Uno, Rocky Marciano, se meaba de gusto al verme llegar a altas horas y la otra, la gata Cayetana, se limitaba a mirarme, con sus ojos de emperatriz de cómic [...], en «El asesino de Getafe», 30.04.04, u.p.

[...] Desde que Floyd Paterson fue noqueado por el sueco Ingerman Johansson, ningún negro había recibido un abucheo semejante [...], en «Un microchip para Powell», 06.09.02, u.p.

Estos púgiles negros son traídos a las columnas en comparación con políticos nortemericanos del mismo color:

[...] En cuanto a Obama, se ha convertido en la esperanza negra. En boxeo se ha estado llamando la 'esperanza blanca’ a todos los púgiles más o menos pálidos que disputaban el mundial de los pesos pesados desde el imbatible Joe Louis. Salvo el interregno de Rocky Marciano, todos los grandes campeones son de epidermis oscura. En esta ocasión, el combate ha sido muy duro y ha apasionado a más gentes que en ninguna otra votación. También ha generado más esperanza [...], en «Después del desenlace», 06.11.08, u.p.

El último gran campeón fue el Cassius Clay de los años 60. Si «Rocky Marciano había sido la potencia, Clay fue la habilidad, 'la esgrima', el arte. Las piernas de Clay han creado el baile del boxeo, una danza felina 
practicada por un cuerpo de noventa kilos. «Casi increíble», afirmaba Manuel Vázquez Montalbán (1972: 246). Alcántara lo menciona para comparar el caso de su polémica conversión espiritual con la de un talibán norteamericano que fue noticia en su momento:

[...] Este talibán criado en California se convirtió al islamismo a los veinte años y aprendió árabe. «Mi corazón quedó prendido y decidí unirme a ellos», ha dicho. Algo parecido le ocurrió a Cassius Clay, que cambió su nombre por el de Mohamed Alí y se enfrentó a su propio país desde la isla cuadrada del 'ring', sin más armas que sus músculos de gomaespuma» [...], en «El prisionero», 05.12.01, u.p.

Entre los españoles, dos son los boxeadores que tienen mayor presencia en sus textos: Paulino Uzcudun y Urtain, las dos figuras de los pesos pesados en diferentes épocas y con distinto destino. De Paulino Uzcudun, del período de entreguerras, dice Vázquez Montalbán (op. cit., p. 114) que «aguantó las palizas más terribles de la historia del boxeo. Este encajador de excepción fue el prodigio de valor y tozudez. Al final de la década de los años 30 era un boxeador gastado, sin títulos oficiales pero con un gran crédito mundial de bravura».

En el siguiente ejemplo, el boxeo no se libra de la denuncia por su relación con el hampa. Excluyendo el dogmatismo y las ganas de moralizar, Manuel Alcántara, con gran sentido del humor, desliza una sutil pero firme crítica:

[...] Paulino Uzcudun decía que Al Capone era el tipo más simpático que había conocido en su vida, mientras me enseñaba una foto en la que aparecía cogido del brazo armado del insigne mafioso [...], «Reliquias», 16.04.92.

Las diferentes formas en que se puede ganar un combate de boxeo le sirven a Alcántara para preguntarse jocosamente cómo se habrá producido la derrota definitiva del gran oponente de Dios:

[...] Gracias a la OTAN, la iglesia ortodoxa ha descubierto que Slobodan Milosevic es el demonio de paisano. Es curioso que esto ocurra dos días después de que la Iglesia católica, por boca de Su Santidad, nos haya dado a conocer que «Satanás ha sido derrotado definitivamente». No ha especificado el Papa Juan Pablo II si la derrota ha sido por K.O., a los puntos o por abandono, pero sin duda es una buena noticia para los creyentes [...], en «El demonio en persona», 21.08.99, u.p.

El otro boxeador español que Alcántara lleva a sus columna, al que conoció muy bien y cuya carrera siguió desde Marca, es José Manuel Ibar, Urtain, llamado “El Morrosko de Cestona” y “El Tigre de Cestona”. Precisamente se lamenta de su pronta muerte, junto con la del futbolista internacional Juan Gómez 'Juanito':

[...] ¿Por qué se murieron tan pronto los futbolistas Juanito y el boxeador Urtain? Con los dos tenía citas aplazadas. No se puede aplazar nada. Todo es ahora o nuca [...], en «Aquí estaban», 02.01.93, u.p. 


\subsection{El boxeo y el jazz como redención para la gente 'de color'}

El boxeo es un juego de tradición antigua -se jugaba en la Ilíada-, de perfil apolíneo y de 'dimensión vertical' (Giménez Caballero, 2000: 16 y ss.), que sirve para que los marginados puedan ascender socialmente por el procedimiento de dar golpes y golpes enguantados.

El boxeo es la venganza elegante de los vencidos, la representación «del honor», «la caballería», «la regla», «la ley», «el orden». Y el guante simboliza lo que la espada feudal entre los burgueses o el martillo manual del proletariado: el instrumento para abrise camino golpeando «brutalmente», «liberalmente».

Para Giménez Caballero, esa «imagen obsesionante» que se ha repetido «en el espejo innumerable de todos los rings mundiales» del boxeador con el puño alzado en alto -vertical- tiene algo de Estatua de la Libertad.

Sobre el protagonismo que tienen los marginados, generalmente de 'epidermis oscura', en el pugilato, Alcántara resalta en sus columnas que los grandes campeones han sido negros que, cuando alcanzan el éxito, el público los ve con menos color:

[...] El racismo es cuestión de pasta. Un campeón mundial de los pesos pesados, archimillonario, lo dijo de modo insuperable: «Yo también fui negro, cuando era pobre» [...], en «Completar el aforo», 21.01.03, u.p.

[...] Más de 500 inmigrantes, nunca están bien contados y pueden ser algunos más o algunos menos, esperan en chabolas un trabajo en la fresa de Huelva. Esto les pasa no sólo por no tener papeles, sino por no tener dinero. Si lo tuvieran dejarían de ser inmigrantes, del mismo modo que los negros campeones del mundo de boxeo, a partir de conquistar el título, dejan de ser negros [...], en «El postre», 03.03.04, u.p.

[...] A las gentes de epidermis cobriza se las cargó casi en su totalidad el Séptimo de Caballería, pero tuvieron buen cuidado en dejar a algunos representantes en las reservas, para atracción de turistas y para que fumaran en pipa. Y a los negros se les hizo trabajar como negros. De vez en cuando, de las plantaciones de algodón, salía un tipo como Joe Louis y ya sabemos que cuando alguien de epidermis oscura es millonario y célebre, destiñe [...], en «Un oscuro plan», 08.05.04, u.p.

[...] Los norteamericanos siguen detestando con fuerza dos cosas: la discriminación racial y los negros. Cuando el primate Mike Tyson, que ha sido el mayor puncheur en corto de la historia cuadrada del boxeo, fue acusado de violar a una congénere, aspirante a miss, en una habitación de hotel, le metieron en la cárcel (...) Ahora, Paula Jones, que es blanca, acusa al presidente Bill Clinton, que es más blanco todavía, de acoso sexual [...], en «Habitación de hotel», 14.01.98, u.p.

Muy cerca del boxeo, Manuel Alcántara introduce en sus columnas el jazz; las dos únicas salidas para un negro norteamericano, a no ser que se sea muy inteligente como el columnista supone que lo son Condo- 
leezza Rice (Consejera de Seguridad Nacional estadounidense) y Colin Powell (Secretario de Estado norteamericano) o se llegue a la presidencia de Estados Unidos, como Obama. Entonces, una tercera vía liberadora de su marginación es la política:

[...] Bastante dura es la vida de un trabajador en Alemania. Hasta el punto de que puede afirmarse que, para un currante, nacer allí supone una mala suerte aproximadamente igual a la de ser negro en los Estados Unidos. Sólo que éstos tienen dos posibilidades de evasión, el jazz y el boxeo, y los alemanes pertenecientes al proletariado tienen una: entrar en una fábrica, que muchas veces es la misma [...], en «Cuando sean mayores», 08.03.04, u.p.

[...] Una solución sería [para los 460 inmigrantes subsaharianos que se encuentra en un barco a la deriva], hasta que algún puerto los acogiera, introducirles en el boxeo o en el jazz, que son las salidas más habituales para la gente de otro color, pero están muy débiles para soplar y para boxear [...], en «Un plan de reparto», 02.09.01, u.p.

[...] Tradicionalmente, solo les hemos dejado dos opciones, aparte de esquilar borricos al compás de los panderos: el cante o la media verónica. Si alguien llega a ser Camarón o Rafael de Paula, ya no tiene problema. Su condición de gitano pasa a segundo término. Ocurre igual que cuando un negro americano llega a campeón del mundo de boxeo o a figura del jazz: deja de ser negro. La trompeta dorada o el crochet de izquierda cambian de modo radical el color de su epidermis. Insuperablemente lo dijo Larry Holmes, el hombre que destronó a Cassius Clay, cuando este ya no era Clay, sino Mohammed Alí: «Yo también fui negro: cuando era pobre» [...], en «Romancero payo», 29.07.94, u.p.

[...] Lo ha anunciado el secretario de Estado, Colin Powell, que es un negro listísimo, y en el mismo sentido se pronunció la consejera de Seguridad Nacional, Condoleezza Rice, que es una negra listísima. (Para alcanzar esos puestos en ese país hay que tener una superpoblación de neuronas si se tiene la epidermis oscura. Hasta hace muy poco los dos únicos caminos de redención para su raza eran la tarima del 'jazz' y la del 'ring') [...], en «El rearme», 13.03.02, u.p.

[...] Obama ha dejado de ser negro porque es presidente de los Estados Unidos. El salto cualitativo que se ha dado con él desborda todos los ránkings. Va más allá de Joe Louis y de Martin Luther King. Muchos confiaron su redención en el último momento, antes de tiempo pero no a deshora, y otros muchos lo habían hecho anteriormente [...], en «Resistencia de los metales», 07.11.08, u.p.

[...] También podía haber dejado correr sin duelo sus lágrimas el señor letrado [de un preso hispano que ha sacado del corredor de la muerte en EEUU], ya que va aumentar su clientela, especialmente entre chicanos y negros con algún poder económico, que también los hay, sobre todo si se dedican al boxeo o al jazz, esas dos tarimas que son la tabla de salvación para los pobres [...], en «Inocente», 08.06.01, u.p. 


\subsection{Comparaciones entre situaciones de la política y el boxeo}

Manuel Alcántara establece comparaciones entre la situación política, tanto española como norteamericana, con el desarrollo de un encuentro boxístico:

[...] Hablaba del golpe de efecto del señor Zapatero, al que todavía no llaman Dios como a Felipe González en ciertas épocas de esperanza. Ha descalificado los presupuestos por «antisociales y antiguos». Los precios de la vivienda, la creciente inseguridad ciudadana y la educación salieron a relucir. Fue lo que en boxeo se llama un 'lucky punch', un golpe en frío que le ha hecho ganar el primer asalto. De todas maneras, el combate es más largo [...], en «Primer asalto», 24.10.02, u.p.

[...] El combate electoral ha empezado antes de tiempo. Lo ha iniciado el presidente Aznar, que sabe que a quien madruga Dios le ayuda y tampoco ignora que a su enmascarado sustituto va a hacerle falta Dios y ayuda para ganar las próximas elecciones [...], en «Primer asalto», 12.11.02, u.p.

[...] No es un mal ejemplo Jaume Matas, que ahora no tiene quien le escriba y antes no tuvo quien quisiera pactar con él. No ha perdido el combate por KO, sino por abandono [...], en «Perder por abandono», 25.06.07, u.p.

[...] Asegura Borrell que tiene más posibilidades que su competidor de derrotar por puntos a Aznar en el próximo combate electoral [...], «Ya empezamos», 18.04.98, u.p.

[...] Tampoco hay que descartar la hipótesis de que el general Powell, que tiene pinta de ser campeón del mundo de los semipesados, le metiera un crochet de derecha ante algunas discrepancias sobre la táctica más adecuada para matar afganos [...], en «La coartada de Bush», 16.01.02, u.p.

[...] Visto desde fuera, resulta extraño que en el partido socialista, que no hay que olvidar que perdió el último combate por escasísimo margen de puntos, haya tanto recelo a la relativa novedad [...], en «Recado de escribir», 12.04.98.

Si en los ejemplos anteriores Alcántara precisaba los nombres propios de los mandatarios políticos, en los de ahora también emplea la imagen del boxeo para opinar de política en general:

[...] La política, como el boxeo, es una profesión durísima salvo para los que se instalan y permanecen en la cumbre. Si se es un segunda serie existe el peligro de terminar de consejero de algo o de portero de discoteca (...) Los más fornidos porteros de discoteca no resistirían más allá de dos asaltos con cualquier boxeador de segunda serie, pero son aptos para rechazar gamberros inermes [...], en «Desbandada», 12.04.02, u.p.

[...] La popularidad de los políticos, como los combates de boxeo que llegan al límite de los asaltos previstos, se mide por puntos [...], en «Muchos puntos menos», 20.02.03, u.p. 
[...] Habrá más guerras, eso está claro, pero algunos discrepan del motivo. ¿Será el combate de revancha de Las Cruzadas y se planteará entre el Islam y Occidente? Einstein tenía por seguro una cosa, fuese una u otra la causa: que la próxima se haría con piedras [...], en «La próxima», 22.03.06, u.p.

Dentro de este punto, la imagen del combate nulo o 'match' nulo, esto es, el que no gana ninguno de los dos contendientes, le sirve al columnista para reflejar el desacuerdo humano, tan frecuente en política como en la vida:

[...] Lo que parece improbable es que el resultado, al borde del 'match nulo', haya estado influido por el anteproyecto de ley para la violencia doméstica [...], en «Llegan los intérpretes», 15.06.04. El Correo, u.p.

[...] Unos quieren que haya vencedores y vencidos y, como están de luto, no se resignan al 'match nulo' [...], en «Mucha marcha», 21.02.06, u.p.

[...] se debate si había antes más corrupción que ahora o ahora hay más corrupción que antes -muchos creen que el resultado del combate debe ser nulo- [...], en «Vivir es perjudicial para la salud», 04.02.92.

[...] La conversación mantenida entre Fidalgo y Cándido Méndez con Rato y Zaplana ha terminado en combate nulo. Por lo tanto, no ha terminado. Habrá que programar un nuevo 'match' [...], en «La amenaza», 28.07.02, u.p.

[...] Según el último barómetro del CIS, que registra el tiempo político, el PSOE recorta a 4,2 puntos la ventaja del PP. A muchos no les ha extrañado en absoluto ese recorte, sino que la ventaja existiera. A otros, por el contrario, lo que les asombra es que la diferencia no sea mayor. La cosa siempre ha estado bastante igualada, hasta el punto de que en algunas elecciones puede darse el resultado de combate nulo. Las célebres dos Españas siguen coexistiendo, aunque de forma más civilizada que en cualquier otro periodo de nuestra convulsa historia [...], en «El recorte», 23.08.02, u.p.

[...] Cualquier equilibrio, por muy precario que sea, es mejor que el enfrentamiento y las encuestas dan combate nulo [...], en «Bajo mínimos», 09.01.07.

\subsection{El boxeo como espejo de otras situaciones}

Asimismo, vemos cómo establece comparaciones entre colectivos y situaciones de dispar índole con distintos aspectos del boxeo:

[...] Como en algunos combates de boxeo, el veredicto se produjo por "decisión dividida", o sea, por una discutible apreciación de puntos que otorgó un margen de cinco votos, entre 563 miembros del sínodo [...], en «Sacerdotisas», 13.11.92.

[...] También hay quien cree que el aumento de las separaciones se debe a que ahora la gente no aguanta un pelo, 
o sea, que no encaja los golpes, en argot de boxeo. Pero los lanza [...], en «Parejas rotas», 18.11.99, u.p.

[...] Todavía son muchos los compatriotas persuadidos de que la mujer no es sólo su sierva, sino su 'sparring' [...], en «Florentino debe interceder», 18.09.02, u.p.

[... ¿ ¿A quién demanda un poeta lírico por no tener dinero? Tampoco es lícito que lo haga un boxeador si estaba cogiendo moscas en recintos cerrados. Sabía a lo que se expone todo el que se sube a un ring, del mismo modo que todo el que tenga un inmediato superior sabe que está expuesto a contraer una úlcera de estómago [...], en «Los demandantes», 24.11.02, u.p.

[...] En cualquier profesión hay personas que para encontrar «el pasadizo que hay de un cuerpo a otro» se inclinan por los de su mismo sexo: toreros, académicos, boxeadores, carteros y no digamos poetas, donde no hay números clausus [...], en «La capa del cura», 05.02.02, u.p.

[...] Mucha gente vive del porcentaje, no sólo los 'managers' de los boxeadores [...], en «El porcentaje», 12.03.01, u.p.

[...] Todo vale para mermar el prestigio de la persona a batir: reemplazar la daga por el cuchillo cachicuerno y sustituir los guantes de ocho onzas por la garrota [...], en «El arte de moder», 08.10.08, u.p.

[...] Todos los años se celebran varios encuentros de fútbol a los que se denomina el partido del siglo y varios combates de boxeo a los que se llama el combate del siglo. Más modestamente, al asunto de los multimillonarios sobresueldos que se embolsarán los directivos de Telefónica con el truco legal de sus stock options se le está conociendo como el escándalo de la década [...], en «El escándalo de la década», 11.11.99, u.p.

El siguiente ejemplo se refiere a una columna que trata de la crisis y que nada tiene que ver con el boxeo que ni siquiera menciona en el texto. En él, Alcántara toma el título de la novela Más dura será la caída y crea uno nuevo para titular su columna. Sobre el nombre propio del título de una obra de creación existente (Fernández Leborans, 1999) opera un cambio originando así, además de una intertextualidad, una denominación original. En concreto, un nombre propio de carácter neológico (Sánchez Gómez, 2008):

«Más blanda será la caída», 10.10.08, u.p.

En otros textos, los tres minutos que dura un asalto en boxeo son la medida temporal de todas las cosas:

[...] Hay que tener en cuenta que muchos parlamentarios son incapaces de articular un parlamento cuya duración exceda de tres minutos, que es lo que dura un asalto en un combate de boxeo [...], en «Preguntas», 17.01.02, u.p.

[...] Una consulta médica dura menos que un 'round' de boxeo y bastante menos que un orgasmo, que según un amigo mío debiera durar, al menos, lo mismo que el himno nacional [...], en «Visto y no visto», 23.03.01, u.p. 
El columnista también compara el dramático boxeo y sus practicantes con otros deportes y deportistas:

[...] No es normal, entre los futbolistas, una recta final como la de tantos y tantos boxeadores. Maradona no puede acabar como sus paisanos Mono Gatica o Ringo Bonavena. Sería una pena y un atentado contra los cromos antiguos [...], en «La deuda de 'Pelusa'», 06.02.99, u.p.

[...] El vicepresidente lleva poco tiempo practicando este deporte [el patinaje] que es menos arriesgado que el boxeo, pero más que el ajedrez [...], en «Los esquiadores», 08.01.98, u.p.

[...] No sólo necesitan estímulos los ciclistas que hacen etapas de 250 kilómetros bajo un sol de injusticia o los boxeadores que dan y reciben golpes durante doce asaltos, bajo la luz de quirófano del ring. En la contienda sentada del ajedrez también existe el dopaje [...], en «Jaque al doping», 16.11.99, u.p.

\subsection{Comentarios pugilísticos}

El conocimiento de boxeo que tiene el ex cronista le permite incluir en sus textos comentarios y disgresiones sobre este deporte, del que Alcántara tiene serias dudas de que lo sea:

[...] Siempre hay un pésimo aficionado, mejor dicho, espectador, que en medio de un combate de boxeo lanza un grito que juega a cuatro esquinas del ring: iqueremos sangre! [...], en «Hacer sangre», 20.05.04, u.p.

[...] Muy difícil se lo van a poner ahora a los porteros de discoteca, que suelen ser boxeadores retirados que no tuvieron mucha fortuna en el ring. (A mi pobre amigo Urtain, en los principios de su carrera, le trajeron algunos de los que ahora hacen de guardianes de salas de fiesta. Los tiraba en el primer asalto o en el segundo. Él era inocente. El tongo en boxeo sólo lo sabe uno: el que va a caer) [...], en «Apariencias», 30.01.03, u.p.

[...] La vida es un deporte terrible, aunque no esté claro que sea un deporte. Cuando Joyce Carol Oates escribió su libro sobre el boxeo trató lo que es ser pobre y obstinado y, sobre todo, lo que es saber triunfar [...], en «Resistencia de los metales», 07.11.08, u.p.

[...] En otras ocasiones hay que pagar la entrada y al parecer eso otorga al público un alto grado de respetabilidad. He oído chillarle a Espartaco, en la plaza de las Ventas, ¡becerrista!, cuando había matado cerca de mil toros. Haber satisfecho el importe de la localidad legitimaba, a su juicio, a aquel espectador de voz poderosísima (...) Como algo sabe uno de ese bárbaro y emocionante deporte que quizá no sea deporte, sospeché que los dos muchachos que habían hecho match nulo, en una pelea sorda y enredada, se habían infligido un duro castigo. Bajé al vestuario. Los dos contendientes estaban hechos polvo. Se temía por la vida de uno de ellos y los médicos hacían lo que podían, mientras llegaban los gritos de ¡tongo!, ¡tongo!, ¡tongo! de los clarividentes espectadores [...], en «El público, tan respetable», 04.03.98, u.p. 
En este último ejemplo -que arranca con un guiño a Borges-desliza, junto al boxeo, una referencia a los toros, otra de las pasiones que tampoco oculta Alcántara:

[...] Además de bajo la especie de biblioteca, como el reciente clásico, sueño el paraíso como espectador de algunos lances imposibles, por ejemplo, un combate de Joe Louis con Mike Tyson, o una corrida donde se lidiaran seis victorinos en la que interviniesen Joselito, Belmonte y Manolete, o un mano a mano entre Cúchares y José Tomás, para ver cómo han cambiado las maneras de entender esa estatutaria fugitiva y dramática que es el toreo [...], en «Cartel», 11.12.99, u.p.

\subsection{La figura del boxeador como modelo descriptivo}

Alcántara toma como modelo descriptivo a los boxeadores, con los que describe físicamente a diversos personajes del mundo de las artes plásticas, la política, la literatura, entre otros:

[...] Por aquél remoto entonces, Gastón Baquero tenía pinta de campeón de peso pesado meditando su retirada del ring [...], en «Gastón Baquero», 17.05.97.

[...] Sólo Beiras, con su pinta de ex campeón de los semipesados, ha sido sincero, lo que en política es una dudosa virtud [...], en «Vuelven los intérpretes», 24.10.01, u.p.

[...] El hermano de don Juan Guerra que es un gran puncheur [...], en «El guardarropa», 11.06.90.

[...] Cuando a Primo Carnera, aquel gigante italiano que fue efímero campeón mundial de los pesos pesados, le presentaron al duque de Windsor, dijo: «Tanto hablar de este hombre y no es más que un 'welter’» [...], en «La subasta», 22.02.98, u.p.

[...] De tanto vivir ha muerto Pepe Vela Zanetti, pintor y hombre. Le conocí a su regreso de un largo exilio que no había logrado que hospedara rencores. Tenía un aire de ex-campeón de los pesos pesados [...], en «Vela Zanetti», 06.01.99, u.p.

[...] Es mucha la desigualdad entre los contendientes y no sólo de peso, sino de peso específico. Bush es un superwelter, un medio cuando se infla de comer palomitas y Hussein es un peso pesado [...], en «El desafío», 28.02.03, u.p.

\section{Conclusiones}

1. Los referentes del boxeo son un lugar común de las columnas personales de Manuel Alcántara en la prensa generalista (Vocento). El tema del pugilismo está presente en 75 de las 1.500 columnas analizadas, lo que equivale al 5\% de la muestra. En estas columnas, el tema del boxeo se presenta de tres maneras di- 
ferentes: como una simple mención argumentativa (60 casos), como un motivo organizador de toda la estructura de la columna (10) y en muy contadas ocasiones (5) es el tema central de la misma.

2. La presencia regular del boxeo en estas columnas personales de tema libre desvelan que Manuel Alcántara tiene interiorizado el lenguaje de lucha y la literatura pugilística. Por ello, este léxico especializado se desliza en sus columnas independientemente de los temas tratados. Alcántara hace suyas las expresiones de los personajes novelísticos de la literatura pugilística lo mismo dentro (cfr. ej. no 4) que fuera de la columna (cfr. Bibliografía, Astorga, 2008).

3. Es precisamente la libertad de escritura que admite la columna personal lo que hace que las referencias al boxeo no desentonen en ella. El bajo porcentaje de aparición del tema pugilístico en sus columnas resulta lógico, tratándose la columna de Alcántara de un texto de tema de actualidad y de que la práctica del boxeo ya no lo está. Al menos en la misma manera que cuando Alcántara hacía la crónica pugilística en Marca.

4. El columnista muestra su yo introduciéndose en la columna a través de narraciones autobiográficas y con sus característicos rasgos de humor. En esta investigación solo hemos tenido en cuenta los recuerdos referidos a su etapa de cronista deportivo. Por otra parte, el tratamiento que Alcántara hace generalmente del boxeo atenúa, en algunas ocasiones, la dureza de este deporte, al tiempo que consigue adecuar dichos referentes agonísticos al buen tono habitual apreciable en sus columnas diarias.

\section{Referencias bibliográficas}

Albadalejo, T. (1993): Retórica. Madrid: Síntesis.

Alcántara, M. (1969): “Un cierto olor a podrido”, en Marca, 03.05.1969, p. 7.

Alcántara, M. (1979): “César”, en González-Ruano, C.: Mi medio siglo se confiesa a medias. Madrid: Tebas.

Alcántara, M. (1991): “La muerte juega a las cuatro esquinas”, en Cuenta y Razón, nº 60, pp. 115, 116.

Anónimo (2005): Poema de mio Cid. Madrid: El País.

Aristoteles (1999): Retórica. Madrid: Gredos.

Armañanzas, E. (1993): El color del dinero. El boom de las subastas de arte, acontecimiento cultural en prensa. Bilbao: Rekargi. - (1995): Proyecto docente y de investigación para optar a una plaza de Profesora Titular. Bilbao: Universidad del País Vasco.

- (2008): “Entre el crochet y el endecasílabo. Manuel Alcántara, cronista de boxeo”, en León Gross, T.A. (dir.) y B. Gómez Calderón (ed.): El artículo literario: Manuel Alcántara. Málaga: Servicio Editorial de la Universidad de Málaga con la colaboración de la Fundación Manuel Alcántara, pp. 239-260. 
Armañanzas, E. y J. Díaz Noci (1996): Periodismo y argumentación. Géneros de opinión. Bilbao: Universidad del País Vasco. Armañanzas, E. y F. Sánchez Gómez (2009): “Agôn en el cuadrilátero: el lenguaje de lucha en la crónica de boxeo de Manuel Alcántara" (en prensa).

Astorga, A. (2008): "Manuel Alcántara: el deporte más violento que hago es subir al taburete del bar", en $A B C, 08.10 .08$ (http://www.abc.es/20080810/gente-famosos-latidos/manuel-alcantara-deporte-violento-20080810.html)

Avilés Zugasti, A.J.: «Hay que tener mucha paciencia para ser malagueño», en Málaga Hoy, 19.06.05, pp. 14, 15.

Bernal, S. y A. Chillón (1985): Periodismo informativo de creación. Barcelona: Mitre.

Burgos, A. (1999): “Jaime, no paras ni para almorzar", en El Mundo, 27.04.99 (www.elmundo.es/1999/04/27/ opinion/27N0028.html).

Chillón, A. (1999): Literatura y periodismo. Una tradicion de relaciones promiscuas. Barcelona: Universitat Autònoma. Servei de Publicacions.

Fernández Leborans, M. J. (1999): “El nombre propio”, en Demonte, V. e Ignacio Bosque (eds.): Gramatica Descriptiva de la Lengua Espanola, Tomo 1. Madrid: Espasa-Calpe, pp. 77-128.

Garci, J. L. (1998): “Manuel, de Málaga”, en Alcántara, M.: Vuelta de hoja. Madrid: Taller de editores, pp. 9-12.

Góngora y Argote, L. (1991): Letrillas. Madrid: Castalia. (Edic. de Robert Jammes).

Inda, E. (2008): “Manuel tuvo un sueño”, en Toro, C.: La historia de Marca. El retrato de siete décadas de ilusiones. Madrid: La Esfera de los Libros, pp. 011 y 012.

Lausberg, H. (1991): Manual de Retórica literaria. Madrid: Gredos. Vol. I.

López Pan, F. (1995): 70 columnistas de la prensa española. Pamplona: Eunsa.

López Pan, F. (1996): La columna periodística. Teoría y Práctica / El caso de «Hilo directo». Pamplona: Eunsa.

Ramírez, Pedro. J. (2008): “Las uvas doradas”, en El Mundo, 29.08.07, u.p.

Sánchez Gómez, F. (2008): “Manuel Vázquez Montalbán, columnista y neólogo de nombres propios”, en Tonos. Revista Digital de Estudios Filológicos, n⿳0 XV.

Toro, C. (2008): La historia del Marca. El retrato de siete décadas de ilusiones. Madrid: La Esfera de los Libros.

Perelman, Ch. y L. Olbrechts-Tyteca (1989): Tratado de la argumentación. Madrid: Gredos.

Vázquez Montalbán, M. (1972): Cien años de deporte. Del esfuerzo individual al espectáculo de masas. Barcelona: Difusora Internacional, S.A. 
